\title{
Rearing behavior of rats after amygdaloid, hippocampal, olfactory bulb, cortical, or striatal lesions
}

\author{
ERNEST D. KEMBLE, DANIEL R. STUDELSKA, and JENNIFER A. NAGEL \\ University of Minnesota, Morris, Minnesota 56267
}

\begin{abstract}
Anterodorsal caudate nucleus lesions in rats produced decreased rearing behavior that did not seem secondary to altered activity or emotionality. Amygdaloid, dorsal hippocampal, anterior cortical, or olfactory bulb lesions did not detectably alter rearing behavior. Further investigations of caudate and septal afferent and efferent connections, especially hypothalamic and mesencephalic, are suggested.
\end{abstract}

Septal area lesions in rats produce a persistent reduction in rearing behavior which is not directly attributable to altered activity, motivation, emotionality, or reactivity to various forms of stimulation (Kemble \& Nagel, 1975). This lesion effect also occurs in at least one additional rodent species (Laughlin, Donovick, \& Burright, 1975) and in familiar as well as novel environments (Bengelloun, Nelson, Zent, \& Beatty, in press; Donovick, Burright, \& Swidler, 1973; Kemble \& Nagel, 1975). In view of the prominence of rearing behavior among rodents and of the extensive interconnections of the septal area with other brain regions (see, e.g., Millhouse, 1969; Nauta, 1972; Powell, 1963; Powell, Clark, \& Mukawa, 1968; Powell, Cowan, \& Raisman, 1965), it seemed of interest to explore the effects of damage to other CNS structures on rearing. The present report summarizes a number of such experiments conducted over a 2-year period.

\section{EXPERIMENT I}

\section{Method}

Subjects. The subjects were 78 male albino rats (Holtzman Company) weighing 241 to $398 \mathrm{~g}$ at the time of surgery. Twelve rats (olfactory bulb lesions, $\mathrm{N}=4$; control, $\mathrm{N}=8$ ) were previously tested for wood-gnawing in their home cages (Kemble, 1973). All rats were given ad-lib access to Purina Lab Chow and water during this experiment.

Surgery and histology. All surgery was conducted under clean conditions and employed pentobarbital anesthesia $(45 \mathrm{mg} / \mathrm{kg})$ supplemented by local application of Xylocaine. All rats received 50,000 units of procaine penicillin postoperatively and were allowed to recover for at least 12 days before testing. Amygdaloid $(\mathrm{N}=7)$, dorsal hippocampal $(\mathrm{N}=9)$, and anterotorsal caudate nucleus $(\mathrm{N}=4)$ lesions were produced by passing anodal dc through the uninsulated tip of a stainless steel pin.

This research was partially supported by funds from the Graduate School, University of Minnesota, by the University of Minnesota, Morris, and by NIH Grant HD08206 to Dr. W. W. Beatty. The authors would like to thank Dr. Beatty for support Jf this project. Send reprint requests to Ernest Kemble, Division of Social Sciences, University of Minnesota, Morris, Minnesota ;6267. Daniel Studelska is now at North Dakota State Univerity.
Table 1 presents the stereotactic coordinates (relative to the Bregma, midsaggital suture, and cortical surface) and current parameters used to produce these lesions. Olfactory bulb $(\mathrm{N}=4)$ and anterior cortical $(\mathrm{N}=6)$ lesions were produced by aspiration. Finally, in seven rats (knife-cut group), a thin 4.0mm-wide stainless steel blade was lowered $4.5 \mathrm{~mm}$ below the cortical surface $.4 \mathrm{~mm}$ anterior to the Bregma in an attempt to sever hippocampal-septal connections at the level of the fornix columns. Since lesion effects were tested in five experiments over a 2-year period, separate control groups were assigned to each lesion condition (amygdaloid, $\mathrm{N}=8$; anterior neocortical, $\mathrm{N}=9$; anterodorsal caudate, $\mathrm{N}=6$; dorsal hippocampal and knife cut, $N=10$; olfactory bulb, $N=8$ ). Each control group contained one to three operated control rats. The remaining rats received a scalp incision only.

At the conclusion of testing, coronal or saggital sections, stained with cresyl vioiet or thionin, were prepared for histological examination from all cortical and subcortical lesions. The brains of rats sustaining olfactory bulb ablation were simply inspected for completeness of ablation.

Apparatus. Testing was conducted in a $72.4 \times 61 \times 63.5 \mathrm{~cm}$ open field. The floor and three walls were constructed of $1.2-\mathrm{cm}$ plywood painted flat gray and the remaining wall was of clear $.6-\mathrm{cm}$ Plexiglas. The floor was divided into nine $20.3 \times 24.1 \mathrm{~cm}$ rectangles by thin black lines. A single $60-\mathrm{W}$ bulb mounted in the center of the unpainted plywood ceiling provided $35 \mathrm{fc}$ of illumination at the center of the open field which diminished to $20 \mathrm{fc}$ in the corners for all groups except the caudate and their controls. For these animals, illumination was $25 \mathrm{fc}$ at floor level throughout the open field. Extraneous sound was masked by $90-\mathrm{dB}$ white noise. The open field was housed in an Industrial Acoustics (Model 402A) semi-acoustic cubicle. Observations were carried out from an adjacent cubicle through a one-way vision window. Rearing behavior and activity were scored on Sodeco counters and experimental sessions divided into equal time intervals by 28-V programming equipment. Multiple behavioral measures were scored by two observers. The behavior of caudate $(N=4)$

Table 1

Stereotactic Coordinates (Skull Horizontal), Current, and Duration used to Produce Amygdaloid, Hippocampal, and Striatal Lesions

\begin{tabular}{lcc}
\hline \multicolumn{1}{c}{ Structure } & Coordinates & $\begin{array}{c}\text { Current and } \\
\text { Duration }\end{array}$ \\
\hline Amygdala & $2.0 \mathrm{P}, 4.2 \mathrm{~L}, 8.3 \mathrm{~V}$ & $2.0 \mathrm{~mA} / 20 \mathrm{sec}$ \\
Hippocampus & $2.2 \mathrm{P}, 3.0 \mathrm{~L}, 3.2 \mathrm{~V}$ & $1.0 \mathrm{~mA} / 10 \mathrm{sec}$ \\
& $3.7 \mathrm{P}, 3.0 \mathrm{~L}, 3.2 \mathrm{~V}$ & $1.0 \mathrm{~mA} / 10 \mathrm{sec}$ \\
Anterodorsal Caudate & $1.2 \mathrm{~A}, 2.7 \mathrm{~L}, 4.0 \mathrm{~V}$ & $3.0 \mathrm{~mA} / 20 \mathrm{sec}$ \\
\hline
\end{tabular}




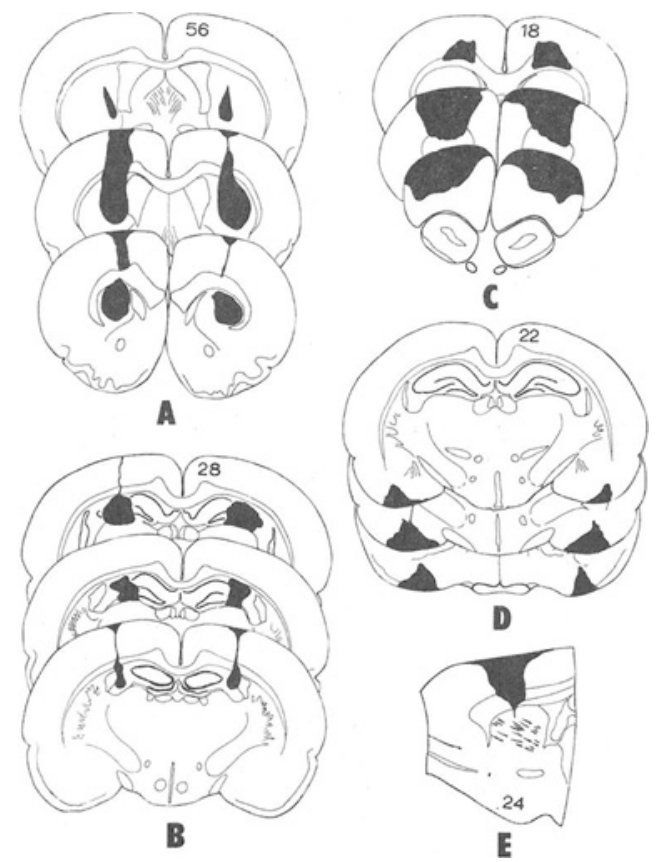

Figure 1. Reconstructions of typical caudate (A), dorsal hippocampal (B), anterior cortical (C), amygdaloid (D), and knife-cut (E) lesions from projected image of stained sections. Most antenor sections presented at the bottom of each reconstruction.

and caudate-control rats $(\mathrm{N}=6)$ was recorded on Memorex/chroma (8010C) videotape by a Panasonic television camera (Model WV-340P) with a wide-angle 8.5-mm Cosmicar lens.

Procedure. For testing, the rat was gently placed in the center of the open field, the ceiling positioned, and the cubicle quietly closed. Behavioral measurements were initiated 50-55 sec later from the adjacent cubicle. A rear was scored whenever both of the rat's forefeet left the floor. Activity was indexed in some groups (dorsal hippocampal, knife-cut, anterodorsal caudate, anterior cortex, and their controls) by the number of rectangles entered with at least one-half of the body exclusive of the tail. Both of these behaviors are simply and reliably (rs $=.93-.99)$ scored. The total number of fecal boli excreted during testing was also recorded. Among caudate-lesioned rats and their controls, the frequency of grooming bouts, floor-sniffing bouts (when the rat's nose was lowered toward the floor), and frequency and duration of inactive periods (no paw movements) were also measured. In addition, the number of times each floor rectangle was entered and the number of times each rat reversed its direction of locomotion was measured among these animals. The floor and lower walls of the apparatus were cleaned with a damp sponge and water after each rat was tested. Anterior neocortical, dorsal hippocampal, knife-cut, and control groups were tested for $10 \mathrm{~min}$ (four $2 \frac{1}{2} 2$-min intervals), amygdaloid rats and their controls for $10 \mathrm{~min}$ (five 2-min intervals), olfactory bulb rats and their controls for $8 \mathrm{~min}$ (eight 1-min intervals), and anterodorsal caudate rats and their controls for $15 \mathrm{~min}$ (five 3 -min intervals). The various test durations used in these groups resulted from changes in equipment availability during the experiments.

\section{Results}

Amygdaloid, dorsal hippocampal, anterior cortical, and anterodorsal caudate lesions invariably included ex- tensive damage to the target structures. Although thr lesions varied somewhat in size and often included sligh damage to surrounding structures (e.g., pyriform cortex corpus callosum, lateral geniculate nucleus), there wa no discernible relationship between either lesion size o damage to surrounding structures and performance. $\mathrm{Ol}$ factory bulb ablations were complete and, in one case included unilateral damage to anterior cortex. All of thi knife cuts $(\mathrm{N}=7)$ intended to sever hippocampal-septa connections were placed anterior to the fornix columns Because both knife-cut and anterodorsal caudate lesion typically included cortical and callosal damage, however the data of the knife-cut animals are included. Recon structions of typical lesions are depicted in Figure 1 The rearing behavior of amygdaloid, dorsal hippo campal, knife-cut, olfactory bulb, anterior cortical and their control rats invariably declined during testin (ps $<.01$ ), but in no case did the lesions produce reliabl group differences (ps $>.10$ ) or Groups by Intervals in teractions ( $\mathrm{ps}>.10)$. These data are summarized in Table 2. The activity levels of dorsal hippocampal knife-cut, anterior cortical, and control rats also decliner steadily during the test, with neither group difference nor Groups by Interval interactions (ps $>.10$ ). The fre quency of defecations of amygdaloid, olfactory bulb and anterior cortical subjects was quite similar to that $o$ control rats (ps > .10). Dorsal hippocampal and knife cut rats, on the other hand, defecated more frequentl: than control rats during testing (ns $<, 07$ )

A comparison of anterodorsal caudate and contro performance is depicted in Figure 2. It can be seer (upper panel) that caudate rats reared consistently les: often than control rats $[F(1,8)=10.48, p<.05]$. The normal rearing behavior of rats in the knife-cut group which sustained extensive cortical and callosal damage dorsal to the caudate nucleus, suggests that the lesior effect did not result from incidental cortical damage among caudate-lesioned rats. Rearing declined in botr groups during the test $(p<.01)$, with no Groups by Intervals interaction $(p>.10)$. Activity levels are de picted in the lower panel of Figure 2. Although there were no reliable group differences $(p>.10)$, it can be seen that the activity levels of rats with caudate lesion: were higher during the first 3-min interval but droppec below control levels during the remainder of the tes 1 $[F(4,32)=9.25, p<.01]$. The activity levels of botr groups declined steadily during testing $(p<.01)$. There

Table 2

Comparison (Rears/Minute) of Lesion Groups and Their Controls

\begin{tabular}{lcrcc}
\hline \multicolumn{1}{c}{ Group } & $\begin{array}{c}\bar{X} \\
\text { Rears/Minute }\end{array}$ & \multicolumn{3}{c}{$\begin{array}{c}\text { Control } \\
\text { Range }\end{array}$} \\
\hline Amygdaloid & 4.7 & $1.8-7.5$ & 5.9 & $2.4-7.6$ \\
Hippocampal & 3.7 & $1.1-5.5$ & 3.7 & $1.2-6.3$ \\
Knife Cut & 4.1 & $.9-7.5$ & 3.7 & $1.2-6.3$ \\
Olfactory Bulb & 5.4 & $2.0-10.5$ & 6.8 & $2.9-10.5$ \\
Anterior Cortex & 3.7 & $1.3-6.1$ & 4.5 & $3.1-7.7$ \\
\hline
\end{tabular}




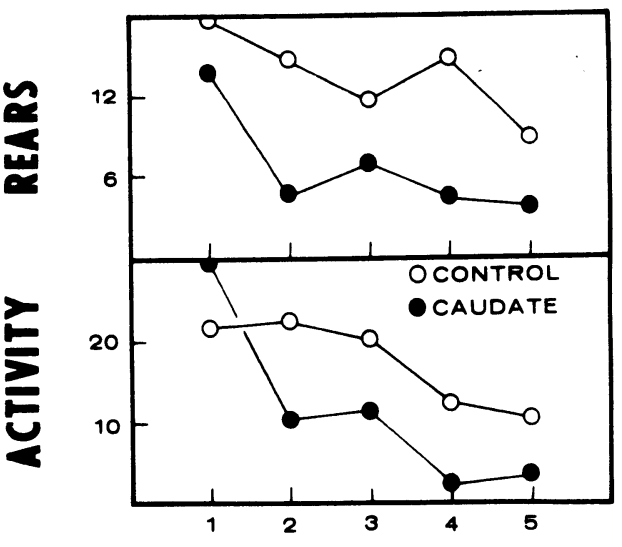

\section{MIN. INTERVALS}

Figure 2. Rearing (upper panel) and activity (lower panel) of caudate and control rats.

were no reliable group differences in defecation (caudate, $\overline{\mathrm{X}}=3.25$; control, $\overline{\mathrm{X}}=1.50, \mathrm{p}>.10$ ). Caudate rats were inactive more often and for a longer total duration than control rats $(p<.05)$. There were, however, no differences in the number of grooming bouts (control, $\bar{X}=9.50$; caudate, $\bar{X}=5.25, p>.10$ ) or floor-sniffing bouts (control, $\bar{X}=103.3$; caudate, $\bar{X}=75.5, p>.10$ ). There were also no significant group differences in the patterns of floor rectangle entry or reversals in direction of locomotion.

\section{EXPERIMENT II $^{1}$}

Among the structures investigated in Experiment I, only anterodorsal caudate nucleus lesions had obvious effects on rearing behavior in the open field. Unlike septal lesion effects (Kemble \& Nagel, 1975), decreased rearing after caudate damage was paralleled by decreased activity during the latter portion of testing. It should be noted, however, that the number of caudate lesions $(\mathrm{N}=4)$, in Experiment I was small. Experiment II investigates caudate lesion effects on rearing and activity with a larger number of rats.

\section{Method}

Subjects. The subjects were 12 experimentally naive male albino rats (Holtzman Company) weighing 334-378 $\mathrm{g}$ at the time of surgery. Six rats sustained anterodorsal caudate nucleus lesions (as in Experiment I), while the remaining rats sustained identical treatment except for current passage.

Apparatus. Testing was conducted in a $114.5-\mathrm{cm}$-square open field with $45.7-\mathrm{cm}$-high walls constructed of plywood and painted flat black. The floor was divided into $22.9-\mathrm{cm}$ squares by white lines. A 60 -W bulb placed $119.4 \mathrm{~cm}$ above the center of the open field yielded $4.4 \mathrm{fc}$ of illumination at the center of the field, which diminished to $2.2 \mathrm{fc}$ in the corners.

Procedures. Each rat was tested for 15 min (five 3-min intervals) on each of 2 consecutive days in the open field. The test began when the rat was gently placed in the center square. Rears were recorded each time the rat's forefeet were lifted from the floor. Activity was indexed by the number of squares entered with both forepaws.

\section{Results}

The results of this experiment are summarized in Figure 3. It can be seen (upper panel) that rats with caudate lesions reared consistently less than their controls $[F(1,10)=4.97, p<.05]$. Although rearing behavior seemed to decrease during the second day of testing, this change was not statistically reliable $(\mathrm{p}>.10)$. There were no Groups by Days or Groups by Intervals interactions $(\mathrm{ps}>.10)$. The activity levels of the two groups are compared in the lower panel of Figure 2. There were no consistent group differences in activity $(p>.10)$ and neither Groups by Days nor Groups by Intervals interactions ( $p s>.10$ ). The activity levels of both groups declined significantly within sessions $(p<.01)$ but there were no reliable changes between Days 1 and 2 $(\mathrm{p}>.10)$.

\section{DISCUSSION}

Decreased rearing behavior seems to be a consistent sequel to anterodorsal ćaudate as well as septal area damage. ${ }^{2}$ Although the caudate effect seemed to be related to hypoactivity in Experiment I, there was no suggestion of group activity differences in Experiment II, while lesion effects on rearing were quite apparent. There have been several reports of increased locomotion following caudate nucleus damage in male rats (Baettig, 1963; Johnson \& Becker, 1973; Kirkby, 1973; Schmaltz \& Isaacson, 1972; Whittier \& Orr, 1962). Of these, Kirkby's (1973) study is the most similar to ours, in that he also observed the effect of dorsally placed caudate lesions on open-field square entry. Besides exhibiting increased locomotion, his caudate lesioned rats defecated more than controls. He conducted additional experiments that indicated these effects were dependent upon stress (which he induced by high illumination levels or food deprivation). Although our lesions were smaller than Kirkby's, the relatively low levels of illumination we employed and the absence of group differences in defecation (Experiment I) suggest that the rearing deficit we observed may be easier to detect under conditions of relatively low stress. It is interesting to note that the dorsal hippocampal and knife-cut groups defecated significantly

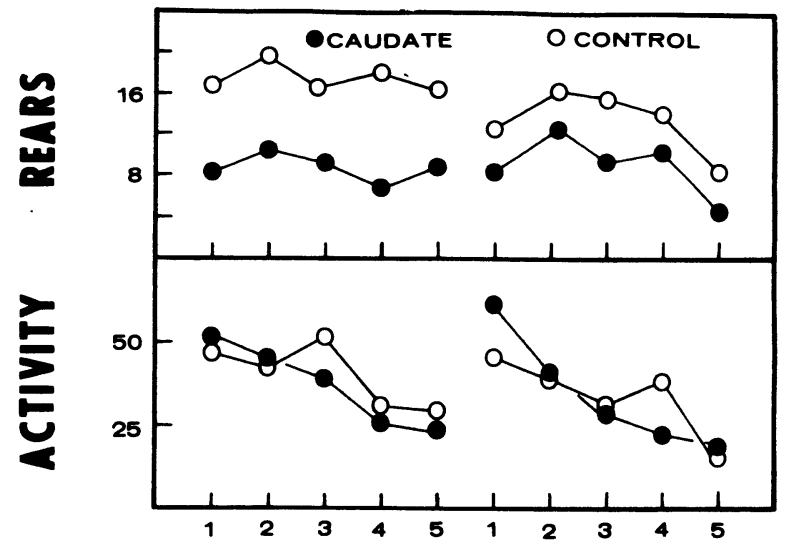

Figure 3. Rearing (upper panel) and activity (lower panel) of caudate and control rats. 
more than control rats in Experiment I but showed normal rearing behavior. These findings are quite consistent with earlier data indicating that lesion-induced alterations in rearing are not secondary to altered activity or emotional/motivational levels (Kemble \& Nagel, 1975).

Although the hippocampus, amygdala, anterior cortex, and olfactory system are known to be extensively interconnected with the septal area (e.g., Nauta, 1972; Powell, 1963; Pcwell, Clark, \& Mukawa, 1968; Powell, Cowan, \& Raisman, 1965; Raisman, Cowan, \& Powell, 1966), damage to these structures was not followed by obvious changes in rearing behavior. It should be remembered, however, that the rats in these experiments were tested under a very limited range of conditions. It is possible that lesion effects would have been detectable in other experimental settings (e.g., with altered forms and/or intensities of stimulation, under food or water deprivation, etc). It is also possible, of course, that the lesions in these experiments largely spared pathways important for rearing behavior. The septal area is also known to make connections with the cingulate cortex, anterior and midline thalamic nuclei, mamillotegmental tract, and medial and lateral hypothalamus via the median forebrain bundle (e.g., Millhouse, 1969; Powell, 1963; Powell, Clark, \& Mukawa, 1968). Although there is no direct evidence, a number of scattered observations suggest that the "downstream" connections of the septal area and caudate nucleus may be important for rearing behavior. Increased rearing and activity have been noted during low-intensity electrical stimulation in and near the median forebrain bundle (personal observations). Epstein (1971) has described "... continuous sniffing at the upper corners of the cage..." immediately after lateral hypothalamic lesions, while Sanders, Lakey, and Singh (1973) describe an almost total absence of cage climbing in mice following goldthioglucose-induced lesions to the ventromedial hypothalamus. These observations suggest that structures lying along the septo-hypothalamo-mesencephalic continuum (Nauta, 1972) and/or the various neurochemical pathways identified in this brain region (e.g., Harvey, 1974) may be importantly involved in rearing behavior. Further investigation of the afferent and efferent connections of the caudate nucleus and septal area is clearly needed for better understanding of this behavior.

\section{NOTES}

1. Experiment II was conducted at North Dakota State University.

2. Subsequent observations by Beatty (personal communication) suggest that lesion effects on rearing are not demonstrable with small anterodorsal caudate lesions.

\section{REFERENCES}

BAETtig, K. Effects of lesions on spontaneous alternation and exploration behavior. Psychological Reports, 1963, 13, 493-494.
Bengelloun, W. A., Nelson, D. J., Zent, H. M., \& Beatty, W. W. Behavior of male and female rats with septal lesions: Influence of prior gonadectomy. Physiology and Behavior, in press.

Donovick, P. J., Burrig̣t, R. G., \& Swidler, M. A. Presurgical rearing environment alters exploration, fluid consumption, and learning of septal lesioned and control rats. Physiology and Behavior, 1973, 11, 543-553.

Epstein, A. N. The lateral hypothalamic syndrome: Its implications for the physiological psychology of hunger and thirst. In E. Stellar \& J. M. Sprague (Eds.), Progress in physiological psychology (Vol. 4). New York: Academic Press, 1971. Pp. 263-317.

HARVEY, John A. Physiological and pharmacological analysis of behavior. In E. Whalen (Ed.), The neuropsychology of aggression. New York: Plenum Press, 1974. Pp. 125-147.

Johnson, D. A., \& BECKER, T. M. Development of open-field activity in the rat following caudate lesions in infancy. Bulletin of the Psychonomic Society, 1973, 1, 331-332.

KEMBLE, ERNEST D. Wood-gnawing in rats following cortical, olfactory bulb, or limbic lesions. Physiolcgy and Behavior, 1973. 11, 735-738.

Kemble, E. D.. \& Nagel, J. A. Persistent depression of rearing behavior in rats after extensive septal lesions. Journal of Comparative and Physiological Psychology, 1975, 89, 747-758.

KIRKBY, R. J. Caudate nucleus and arousal in the rat. Journal of Comparative and Physiological Psychology, 1973, 85, 82-96.

Laughlin, M. E., Donovick, P. J., \& Burright, R. G. Septal lesions in meadow voles and mongolian gerbils: Consummatory and investigatory behavior. Physiology and Behavior, 1975, 15, 191-198.

Millhouse, O. E. A golgi study of the descending median forebrain bundle. Brain Research, 1969, 15, 341-363.

NaUtA, W. J. H. Neural associations of the frontal cortex. Acta Neurobiologica Experimentalis. 1972. 32. 127-140.

Powell, E. W. Septal efferents revealed by axonal degen: eration in the rat. Experimental Neurology, 1963, 8, 406-422.

Powell, E. W., Clark, W. M., \& Mukawa, J. An evoked potential study of limbic projections to nuclei of the rat septum. Electroencephalography and Clinical Neurophysiology, 1968, 25, 266-273.

Powell, T. P. S., Cowan, W. M., \& Raisman, G. The central olfactory connexions. Journal of Anatomy, 1965, 99, 791-813.

Raisman, G., Cowan, W. M., \& Powell, T. P. S. An experimental analysis of the efferent projection of the hippocampus. Brain, 1966, 89, 83-108.

Sanders, M. K., Lakey, J. R., \& Singh, D. Sex differences in hyperphagia and body weight gains following goldthioglucoseinduced hypothalamic lesions in mice. Physiological Psychology, 1973, 1, 237-240.

Schmaltz, L. W., \& Isaacson, R. L. Effect of caudate and frontal lesions on acquisition and extinction of an operant response. Physiology and Behavior, 1972, 9, 155-159.

WhitTier, J. R., \& ORR, A. Hyperkinesia and other physiologic effects of caudate deficit in the adult albino rat. Neurology, $1962,12,529-539$.

(Received for publication May 13, 1976.) 